\title{
CPT PROFILING AND LABORATORY DATA CORRELATIONS FOR DERIVING OF SELECTED GEOTECHNICAL PARAMETER
}

Roman BULKO ${ }^{1}$, Marián DRUSA ${ }^{1,{ }^{*}}$, Jozef VLČEK ${ }^{1}$, Martin MEČÁR $^{2}$

${ }^{1}$ Department of Geotechnics, Faculty of Civil Engineering, University of Žilina, Univerzitná 8215/1, 01026 Žilina.

2 Department of Railway Engineering and Track Management, Faculty of Civil Engineering, University of Žilina, Univerzitná 8215/1, 01026 Žilina.

corresponding author: marian.drusa@fstav.uniza.sk, +421-41-513 5755.

\begin{abstract}
Currently, can be seen a new trend in engineering geological survey, where laboratory analysis are replaced by in situ testing methods, which are more efficient and cost effective, and time saving too. A regular engineering geological survey cannot be provided by simple core drillings, macroscopic description (sometimes very subjective), and then geotechnical parameters are established based on indicative standardized values or archive values from previous geotechnical standards. The engineering geological survey is trustworthy if is composed of laboratory and in-situ testing supplemented by indirect methods of testing, [1]. The prevalence of rotary core drilling for obtaining laboratory soil samples from various depths (every 1 to $3 \mathrm{~m}$ ), cannot be a more enhanced as continues evaluation of strata and properties e.g. by CPT Piezocone (every $1 \mathrm{~cm}$ ). Core drillings survey generally uses small amounts of soil samples, but this is resulting to a lower representation of the subsoil and underestimation of parameters. Higher amounts of soil samples make laboratory testing time-consuming and results from this testing can be influenced by the storage and processing of the soil samples. Preference for geotechnical surveys with in situ testing is therefore a more suitable option. In situ testing using static and dynamic penetration tests can be used as a supplement or as a replacement for the (traditional) methods of surveying.
\end{abstract}

\section{Keywords:}

CPT profiling; In situ data correlations;

Consistency of soil;

Penetration resistance;

Sleeve friction.

\section{Introduction}

The main advantage of static cone penetration testing (CPT) is its speed and continual estimating of soil parameters directly in situ at place of future pile or other foundation where geostatic stress and physical state of soil is intact, see example on Fig. 1. The main principle of CPT is static pushing of mechanical cone or piezocone by set of steel rods into the surveyed soil environment with constant velocity of $20 \mathrm{~mm} . \mathrm{s}^{-1}$. There are measured cone penetration resistance - $q_{c}$, sleeve friction $f_{s}$, and pore pressure $-u_{1}$ or $u_{2}$, which are obtained through continual recording during probing. Soil attributes are expressed with the resistance that the soil applies to resist the penetration of the tip of the probe, $[2,7]$. Changing the mechanical cone to piezocone allows us to measure pore pressures $u_{1}$ (measurement at the tip zone) or $u_{2}$ (measurement closely behind the tip of cone). 


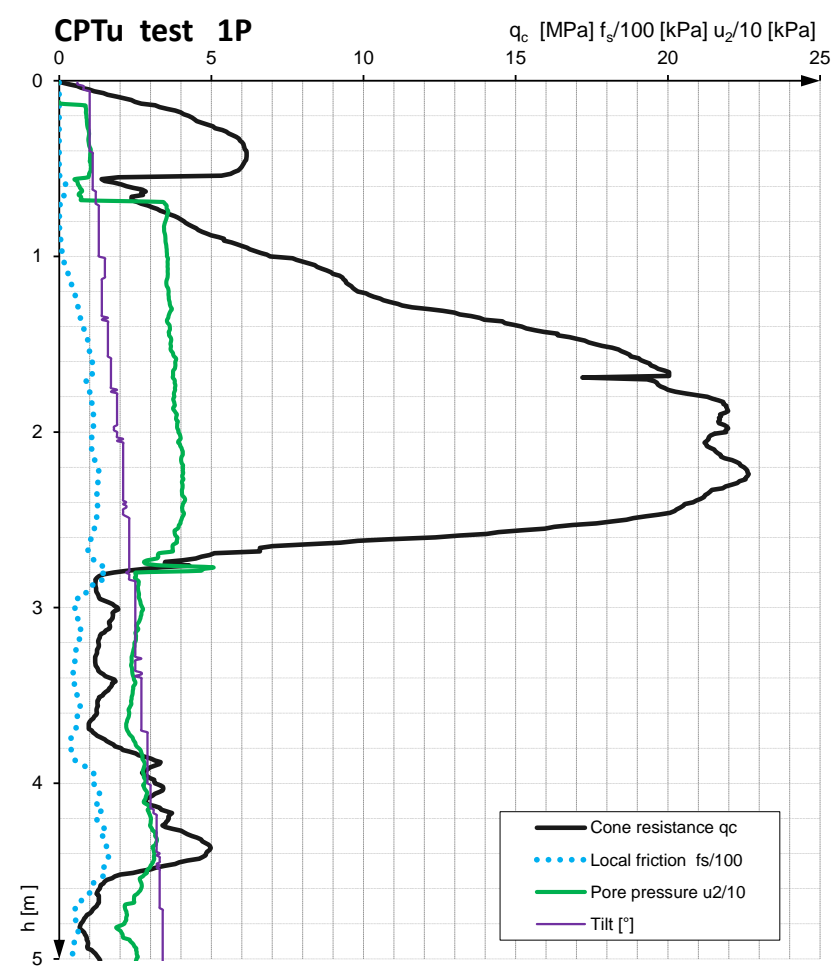

Fig. 1: Sample protocol of CPTu testing at locality Motorway D2 Moravský Sv. Ján.

\section{Derived parameters from CPT testing}

The most suitable method for evaluating the properties of fine-grained compressible soils in subsoil's is static penetration test CPT. The first parameter that was evaluated in laboratory is soil consistency index $I_{C}$, calculated according to formula (1).

At this time, there are several differences in evaluation of soil consistencies, which came into effect after new Slovak Technical Standard (STN 73 6133) and European standards (ISO 14 688-2 and Slovak Standard STN 72 1001), [3]. It means that it is better to describe soil's state with the numerical value of its consistency index instead of describing its state with words. Differences lie in phase transition from its definition, as shown in Fig. 2.

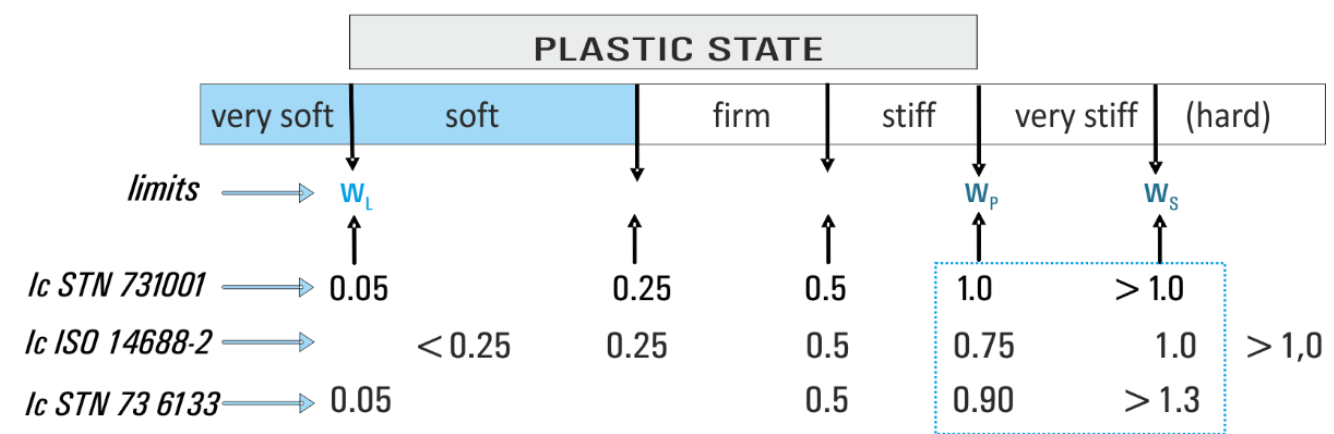

Fig. 2: Consistency of fine-grained soils according to various standards [3].

$I_{C}=\frac{w_{L}-w}{w_{L}-w_{P}}=\frac{w_{L}-w}{I_{P}}$,

where: $w_{L} ; w_{P}-$ are Atterberg's liquid and plastic limit [\%],

$w-$ is a natural water content of soil [\%]. 
In modern soil mechanics $[4,5]$ consistency index is not used frequently like in our geotechnical practice and it is replaced by liquidity index $I_{L}$ (also $\mathrm{LI}$ ), which is calculated from same parameters as consistency index:

$$
I_{L}=\frac{w-w_{P}}{w_{L}-w_{P}} .
$$

Liquidity index is equal to 0 , when soil reach plastic limit and is equal to 1 at liquid limit condition. Consistency index $I_{C}$ is commonly used for description of soil state and there are long years used classification of consistency according to CPT cone resistance $q_{c}$. The relations presented in following Table 1 was used for deriving first CPT correlation to consistency index and there is shown in comparison of consistency intervals from newest standard EN ISO 14 688-2.

Table. 1: Consistency of Soil According to CPT resistance, $[3,6]$.

\begin{tabular}{|c|c|c|c|}
\hline $\begin{array}{c}l c \\
\begin{array}{c}\text { EN ISO 14688- } \\
2\end{array}\end{array}$ & $\begin{array}{c}l c \\
\text { Terzaghi \& Peck } \\
{[2]}\end{array}$ & $q_{c}[\mathrm{MPa}]$ & Description \\
\hline$<0.25$ & 0.05 & 0.0 & very soft \\
\hline $0.25-0.5$ & 0.25 & 0.5 & soft \\
\hline $0.50-0.75$ & 0.50 & $0.5-1.0$ & firm, normal \\
\hline $0.75-1.0$ & 1.00 & $1.0-2.0$ & stiff \\
\hline$>1.0$ & 1.35 & $2.0-4.0$ & very stiff \\
\hline & 1.66 & $>4$ & hard \\
\hline
\end{tabular}

\section{Testing field}

Deriving of correlation dependence between the static penetration tests and laboratory tests must been sure by realization of sufficient and quality laboratory work. For this, experimental test field was used (Fig. 3), which is located within the campus of University of Žilina. On this particular test field, 3 core drillings were realized, one for comparison and other two for the development of other correlations. During each core drilling, four static penetration tests were carried out using a mechanical Begemann cone.

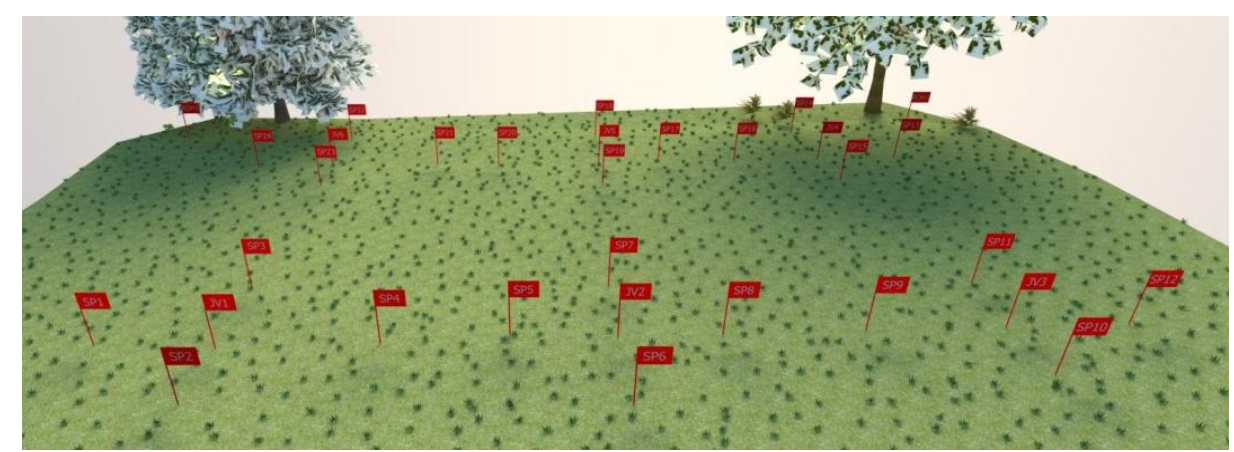

Fig. 3: Model locality with location of core drillings and CPT probes, Uniza testing field.

\section{Deriving of new correlation equations}

For deriving correlation relations between static penetration tests CPT and laboratory tests, it is required sufficient amount of good quality results. Soil samples from core drillings were obtained after intervals of $20 \mathrm{~cm}$, which ensured that the criterion of a sufficient amount of samples was met. The first of the observed parameter was soil moisture. After categorizing the soil type (polygenetic clays of intermediate plasticity $\mathrm{F} 6=\mathrm{Cl}$ ), it was tested liquid and plastic limits, which helped for deriving our first 
considered parameter - consistency index $I_{c}$. The parameter under consideration was calculated continuously from laboratory tests using the expression (1) and then were assigned values from CPT testing (Fig. 1).

After the soil classification and evaluation of the consistency of samples of borehole No.3 and 4, it was created a database of results. This database consists of 75 indexes of consistency. For discovering the concentration, it was drawn XY-type chart (Fig. 4), where on x-axis was plotted penetration resistance $q_{c}$ and on the $y$-axis consistency index $I_{c}$ determined from laboratory tests. With this data series, trend line was drawn to analyze data correlation dependence. It was found a low coefficient of determination, which was due to broad ranges of data. Subsequently it was used manually t-test and z-test to find and exclude very distance data, to improve data fitting.

Based on gradual steps, it was derived a new correlation formula using total penetration resistance $q_{t o t}$, which was suitable for our conditions of closely reassembled laboratory results. For deriving the correlation formula, 76 CPT results from continual measurement (every $20 \mathrm{~cm}$ ) of four penetration probes from the depth interval of 1.0 to $5.0 \mathrm{~m}$ was used. Regression equation is given by (3), the Pearson correlation coefficient $R$ reached 0.88 , and coefficient of determination $R^{2}=0.78$. This indicates that $78 \%$ of Index of consistency is dependent on the total penetration resistance.

$I_{C}=-0.1053 \cdot q_{t o t}{ }^{2}+0.6944 \cdot q_{t o t}-0.16$.

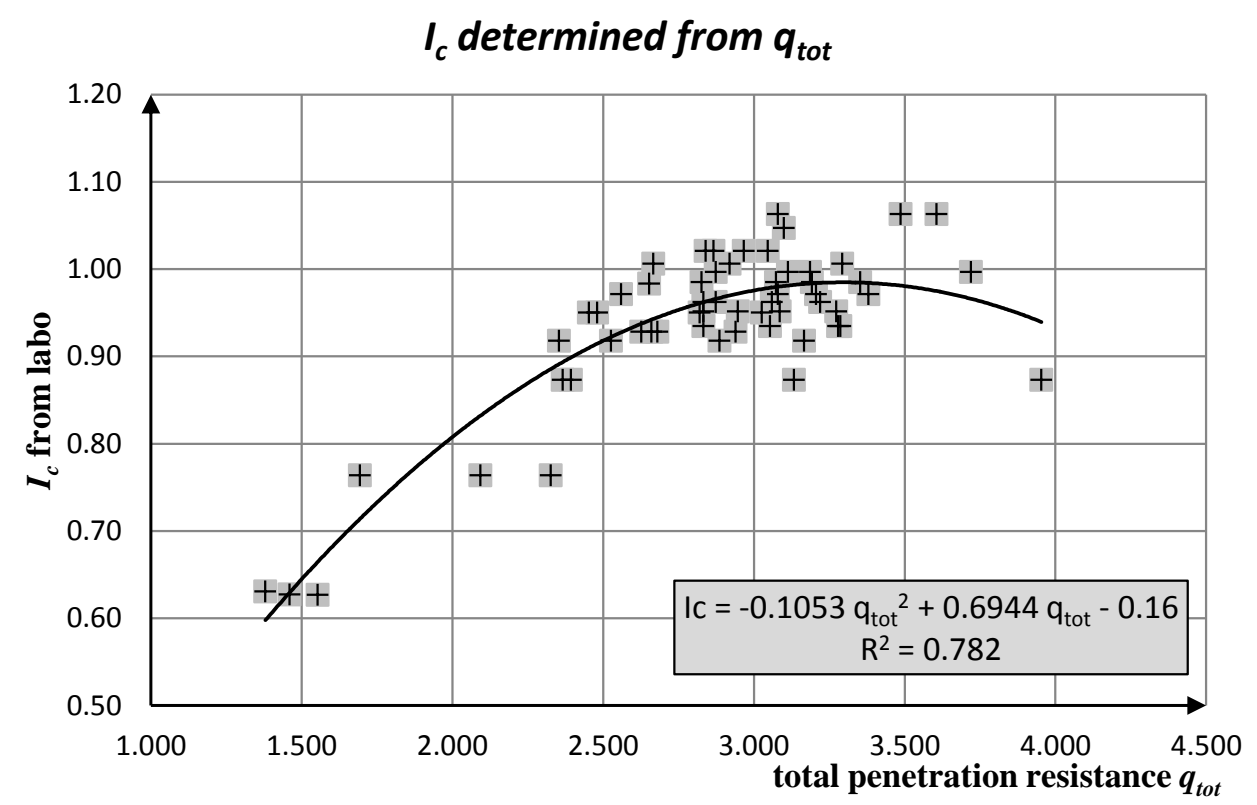

Fig. 4: Correlation of consistency index $I_{c}$ derived from total penetration resistance $q_{\text {tot }}$.

Many authors $[2,6,9,10]$ published relations of consistency index $I_{c}$ to measured cone penetration resistance $q_{c}$, excluding local friction resistance from derived formula. Thus, it was adjusted cone resistance $q_{c}$ to be a normalized penetration cone resistance $q_{c N}(4)$.

$q_{c N}=C_{q} \cdot q_{c} ; \quad C_{q}=\frac{1.7}{\left(\frac{\sigma_{v}}{p_{a}}+0.7\right)}$,

where: $\quad q_{c}-[\mathrm{MPa}]$ is a cone resistance,

$p_{a}-[0.1 \mathrm{MPa}]$ atmospheric pressure,

$\sigma_{v}-[\mathrm{MPa}]$ is a geostatic vertical stress,

$C_{q}[\mathrm{MPa}]$ - stress normalized factor. 
It was derived a new correlation equation for our conditions using the normalized penetration resistance $q_{c N}$, compared with laboratory data from closely obtained soil samples. For deriving the correlation formula it was used 76 results from continual measurements of cone resistance (every $20 \mathrm{~cm}$ ) from 4 penetration probes in the depth interval from 1.0 to $5.0 \mathrm{~m}$. Consistency index derived from normalized penetration resistance is given by (5) with coefficient of correlation $R=0.844$, used data are shown on Fig. 5.

$I_{C}=-0.0001 \cdot q_{c N}^{2}+0.0138 \cdot q_{c N}+0.5772$.

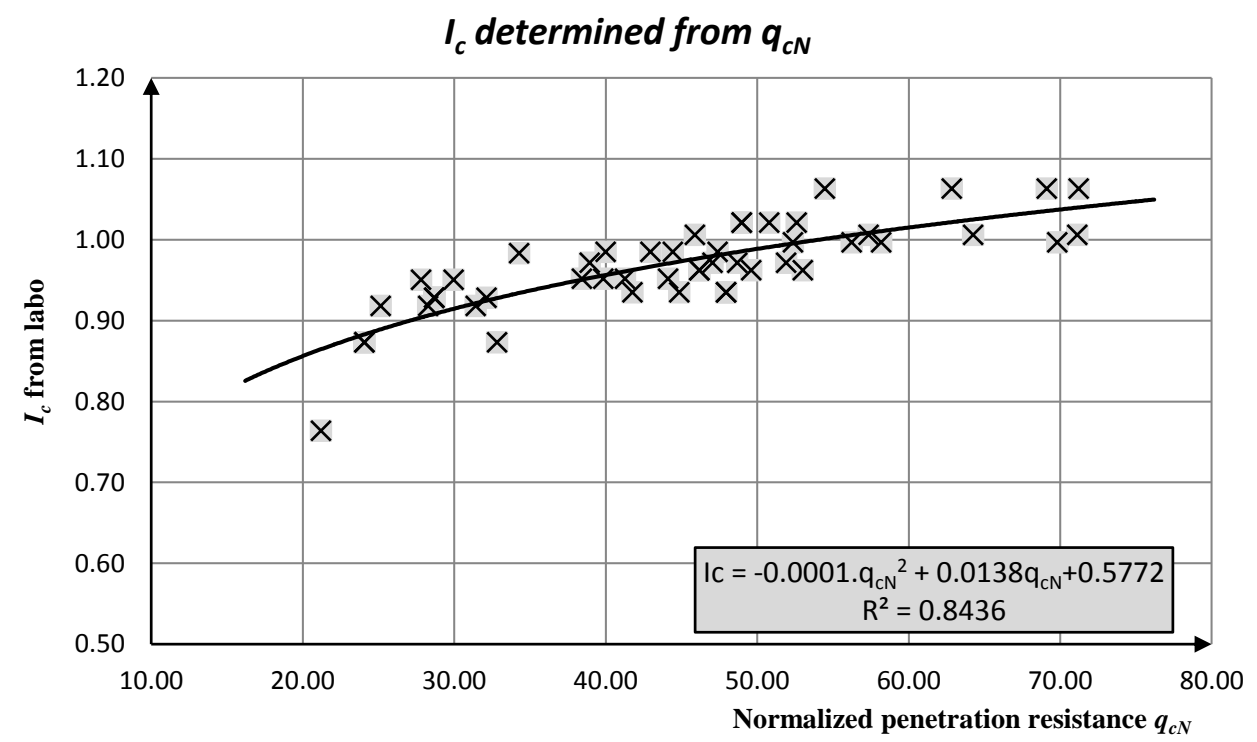

Fig. 5: Consistency $I_{c}$ derived from normalized resistance $q_{c n}$.

\section{Conclusions}

Presently, geotechnical engineering has to face problems of assigning parameters for calculating of difficult geotechnical tasks. For these analyses reliable determination of parameters of soils are strongly required. They can be obtained by CPT testing directly at place of construction activity. The other reasons supporting usage of in situ testing are rapid obtaining of continual information from testing profile, recognition of soil types and its properties [9], estimation of soil parameters, which are in direct connection to designing of geotechnical structures $[8,10]$.

The presented article analyzed in detail consistency index, which is used in many classification standards and is very significant especially in transport constructions and earth structures. In the terms of geotechnical design, consistency index does not enter directly into the calculations of limit states, but based on these values are predicted many other important characteristics, such as water regime in soil subgrade of roads and railway lines, collapse susceptibility, freezing susceptibility. The obtained dataset of laboratory tests and CPT probes will be studied later for clayey mineral activity and their coincidence to selected properties like shear strength parameters.

\section{References}

[1] DRUSA, M. - MEČÁR, M.: Cone penetration testing for evaluations of properties of antropogenous and loess deposits, XVI Russian-Polish-Slovak Seminar, p. 281-285, $11^{\text {th }}-15^{\text {th }}$ June 2007, Žilina, Slovakia, ISBN 5-72640428-9.

[2] DRUSA, M. - CHEBEŇ, V. - MEČÁR, M. - FUSSGÄNGER, E.: Evaluation of properties of neogenous fine soils by CPT testing, Proceedings of XVIII Polish - Russian - Slovak Seminar „Theoretical Foundation of Civil Engineering“, Arkhangelsk, Russia 01 - 05 July 2009.

[3] DECKÝ, M. et al.: 2013. Earth Structures of Transport Constructions. Harlow: Pearson, 2013. ISBN 978-1-78399-925-5. 
[4] MARSCHALKO, M. - YILMAZ, I. - KRISTKOVA, V. - MATEJ, F. - BEDNARIK, M. - KUBECKA, K.: 2011. Determination of actual limit angles to the surface and their comparison with the empirical values in the Upper Silesian Basin (Czech Republic). Engineering Geology. DOI: 10.1016/j.enggeo.2011.10.010.

[5] CHEN, F. H.: Soil Engineering Testing, Design, and Remediation, Edit by M.D. Morris, ISBN 08493-2294-4, CRC Press 2000.

[6] MITCHELL, J. K. - SOGA, K.: Fundamentals of Soil Behavior, $3^{\text {rd }}$ Edition ISBN: 978-0-471-463023, 592 pages, July 2005.

[7] MAYNE, P.W. - CHRISTOPHER, B.R. - DELONG, J.: Manual of Subsurface Investigations, National Highway Institute, FHWA NHI-01-031, Washington DC, 2001.

[8] NGUYEN G: Differences in determination of soil bearing capacity between Slovak Technical Standard STN 731001 and Eurocode 7. 11 ${ }^{\text {th }}$ Conference on Science and Technology. Vietnam National University - Ho Chi Minh City Publishing House, Socialistic Republic of Vietnam, p. 12961303, 2009.

[9] ROBERTSON, P.K.: 1990. "Soil Classification Using the Cone Penetration Test." Canadian Geotechnical Journal, Vol. 27, No. 1, 151-158.

[10]VLČEK, J. - ĎUREKOVÁ D. - ZGÚTOVÁ K.: Evaluation of Dynamic Methods for Earthwork Assessment Civil and Environmental Engineering, Civil and Environmental Engineering, Volume 11, Issue 1 (May 2015), elSSN: 2199-6512, DOI: 10.1515/cee-2015-0005. 